\title{
Determination of technetium in sea-water using ion exchange and inductively coupled plasma mass spectrometry with ultrasonic nebulisation ${ }^{\dagger}$
}

\author{
Ahmet E. Eroglu ${ }^{\ddagger a}$, Cameron W. McLeod ${ }^{* a}$, Kinson S. Leonard ${ }^{b}$ and David McCubbin ${ }^{b}$ \\ ${ }^{a}$ Centre for Analytical Sciences, University of Sheffield, Sheffield, UK S3 7HF \\ ${ }^{b}$ Centre for Environment, Fisheries and Aquaculture Science, Lowestoft Laboratory, Pakefield Road, Lowestoft, Suffolk, UK NR33 0HT
}

\begin{abstract}
An enrichment-separation scheme employing a strong-base type anion-exchange resin was developed for the determination of ${ }^{99} \mathrm{Tc}$ in sea-water by inductively coupled plasma mass spectrometry utilising ultrasonic nebulisation with membrane desolvation. Samples were processed through an anionexchange column to enrich Tc and to eliminate sea-water matrix ions. The limit of detection for ${ }^{99} \mathrm{Tc}$ in sea-water based on processing a $14 \mathrm{ml}$ sample was $0.03 \mathrm{ng} \mathrm{l}^{-1}$. Accuracy was verified with spike recovery experiments. The potential for rapid on-line sample processing via a microcolumn-flow injection system was demonstrated.
\end{abstract}

Keywords: Technetium; sea-water; ion exchange; flow injection; inductively coupled plasma mass spectrometry; ultrasonic nebulisation

Technetium-99 is a $\beta$-emitter with a half-life of $2.1 \times 10^{5}$ years and is released into the environment as a result of nuclear weapons testing and general reactor operations including nuclear fuel reprocessing. The most stable form of Tc is the pertechnate anion $\left(\mathrm{TcO}_{4}{ }^{-}\right)$, which in aqueous solution is stable over a broad range of $\mathrm{pH}$ and $E_{\mathrm{h}}$ values. ${ }^{1,2}$ It has been shown that $\mathrm{TcO}_{4}{ }^{-}$is poorly sorbed by suspended particles in oxygenated sea-water and freshwater systems and so is very mobile; ${ }^{3}$ this makes Tc an ideal tracer for water transport studies. Concentrations of Tc in sea-water are extremely low but relatively high concentrations have been reported for the Irish Sea. In a study by Riley and Siddiqui, ${ }^{4}$ Tc levels of $19-99 \mathrm{ng} 1^{-1}$ (12-63 Bq 1 ${ }^{-1}$ ) were reported, whereas Leonard et al., ${ }^{5}$ more recently, found concentrations of $0.002-0.6 \mathrm{ng} \mathrm{l}^{-1}(1-350$ $\left.\mathrm{mBq} 1^{-1}\right)$.

Given the extremely low concentrations of Tc in the marine environment, determination necessitates an enrichment and separation from the sample matrix prior to instrumental measurement. The most commonly used separationenrichment techniques include coprecipitation with iron(III) hydroxide-organic solvent extraction, ${ }^{6,7}$ ion exchange ${ }^{8}$ and ion exchange-iron(III) hydroxide coprecipitation-organic solvent extraction. ${ }^{9}$ Beta-counting techniques have been the preferred route for quantification. ${ }^{5,8,9}$

As an alternative to radiometric measurement, inductively coupled plasma mass spectrometry (ICP-MS) has been developed by several groups for the determination of Tc in environmental samples ${ }^{6,7,10-13}$ and also the determination of other long-lived radionuclides including, ${ }^{237} \mathrm{~Np}$ and ${ }^{239} \mathrm{Pu}^{14-19}$ As pointed out in several papers, ${ }^{20-23}$ ICP-MS offers several advantages over radiometric measurement, including a relatively short measurement time and high sensitivity with small sample size. There are, however, some drawbacks: the ICP-MS technique may suffer from isobaric overlaps and it is prone to

${ }^{\dagger}$ Presented at the 1998 Winter Conference on Plasma Spectrochemistry, Scottsdale, AZ, USA, January 5-10, 1998.

${ }^{\ddagger}$ On leave from the Department of Chemistry, Middle East Technical University, 06531 Ankara, Turkey. matrix induced interferences, including those associated with oxide and hydride formation. High concentrations of matrix elements may also suppress analyte signals and in addition give rise to signal instability as a result of solid depositions on the interface cones.

The aim of this study was to develop rapid and simple enrichment procedures for Tc in sea-water prior to determination by ICP-MS. A key hardware feature was the use of ultrasonic nebulisation (USN) with membrane desolvation (MD) for high efficiency sample introduction. In a previous study, ${ }^{19}$ the use of USN with MD was shown to reduce ${ }^{238} \mathrm{U}^{1} \mathrm{H}$ levels seven-fold compared with direct USN and this allowed an interference-free determination of ${ }^{239} \mathrm{Pu}$ in sea-water. In this study, the potential interference of ${ }^{98} \mathrm{Mo}^{1} \mathrm{H}$ on ${ }^{99} \mathrm{Tc}$ was not observed. The main experimental programme was focused on analyte separation-matrix removal based on a traditional ion exchange column technique, but the analytical potential was also demonstrated for a flow injection-microcolumn configuration.

\section{EXPERIMENTAL}

Reagents and materials

High purity water (Milli-Q Academic; Millipore, Bedford, MA, USA) and high purity acids (Aristar grade; BDH, Poole, Dorset, UK) were used throughout. An analytical-reagent grade strong anion exchange resin [Amberlite IRA-400 $\left(\mathrm{Cl}^{-}\right)$, mesh size 100-200; BDH] served as the enrichment medium. A $10 \mathrm{ng} 1^{-1}{ }^{99} \mathrm{Tc}$ stock standard solution was prepared in the Centre for Environment, Fisheries and Aquaculture Sciences (CEFAS) laboratory of the Ministry of Agriculture, Fisheries and Food (MAFF) at Lowestoft, UK. Working standard solutions of ${ }^{99} \mathrm{Tc}$ at the sub-ng $1^{-1}$ level were prepared from the stock standard solution by serial dilution. Working standard solutions of $\mathrm{Re}, \mathrm{Mo}$ and $\mathrm{Ru}$ were prepared from the respective $1000 \mathrm{mg} \mathrm{l}^{-1}$ stock standard solutions (BDH).

\section{Sample processing}

Ion exchange columns were prepared with Amberlite IRA-400 $\left(\mathrm{Cl}^{-}\right)$resin as shown in Fig. 1. After preparation, the column was washed with $0.5 \mathrm{M} \mathrm{HCl}(2 \mathrm{ml})$ and high purity water $(2 \mathrm{ml})$. Samples $(14 \mathrm{ml})$ containing Tc and Re were applied to the column using Pasteur pipettes and the column was washed with $0.5 \mathrm{M} \mathrm{HNO}_{3}(2 \mathrm{ml})$. The analytes deposited on the column were eluted with $10 \mathrm{M} \mathrm{HNO}_{3}(5 \mathrm{ml})$. The eluates were then diluted to $14 \mathrm{ml}$ with high purity water after the addition of $1.0 \mu \mathrm{g}^{-1}$ of $\mathrm{Rh}$ as internal standard.

For flow injection preconcentration, microcolumns of Amberlite IRA-400 $\left(\mathrm{Cl}^{-}\right)$resin were prepared using PTFE tubing $(4 \mathrm{~cm} \times 1.5 \mathrm{~mm}$ id $)$. The manifold for flow injection preconcentration utilised a peristaltic pump (Minipuls 3; Gilson, Vilbers-le-Bel, France), a rotary injection valve (Omnifit, Cambridge, UK) and a packed microcolumn as shown in Fig. 2. The two-line system was used such that during 


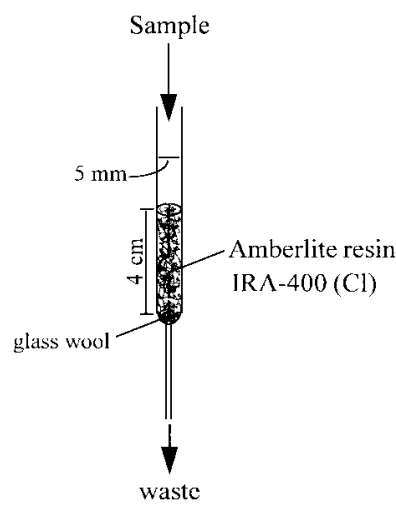

Fig. 1 Schematic diagram of ion exchange technique.

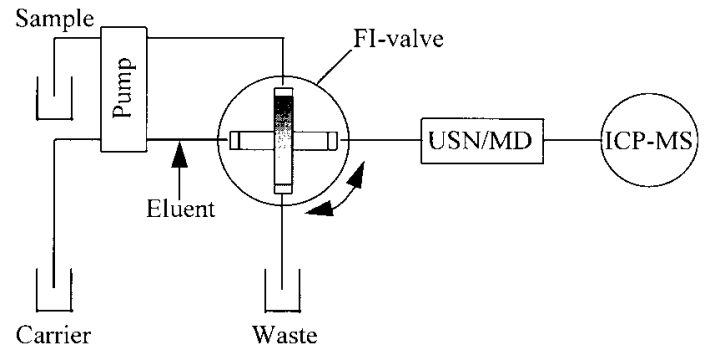

Fig. 2 Flow injection-microcolumn preconcentration manifold.

the deposition cycle analyte underwent deposition on the microcolumn whereas matrix constituents would flow to waste. For the elution step the injection valve was switched to bring the microcolumn on-line and adsorbed species were eluted by injection of eluent $\left(10 \mathrm{M} \mathrm{HNO}_{3}\right)$. The flow rate was maintained at $1.25 \mathrm{ml} \mathrm{min}{ }^{-1}$ in both the deposition and elution stages.

\section{Instrumentation and calibration}

A quadrupole-based ICP mass spectrometer (HP4500; Hewlett-Packard, Avondale, PA, USA) utilising an ultrasonic nebuliser-membrane desolvation system (USN U-6000AT ${ }^{+}$; CETAC Technologies, Omaha, NE, USA) was used in all measurements. Instrumental parameters listed in Table 1 were optimised using a Y standard solution $\left({ }^{89} \mathrm{Y}, 1.0 \mu \mathrm{g} 1^{-1}\right)$. Concentrations of $\mathrm{Tc}$ and $\mathrm{Re}$ (yield monitor) in the samples were calculated from their respective calibration plots, which were obtained using standard solutions of Tc $\left(0.1-2.0 \mathrm{ng} \mathrm{l}^{-1}\right)$ and $\operatorname{Re}\left(0.05-0.2 \mu \mathrm{g}^{-1}\right)$ prepared in $\left.3.5 \mathrm{M} \mathrm{HNO}_{3}\right)$. In all measurements $\mathrm{Rh}\left(1.0 \mu \mathrm{g}^{-1}\right)$ was used as an internal standard. Time resolved analysis software was utilised in FI experiments.

Table 1 ICP-MS operating parameters

Sample presentation -

USN:

Heater temperature

Condenser temperature

MD:

Heater temperature

Sweep gas flow rate

Sample flow rate

ICP-MS -

Carrier gas flow rate

Masses monitored

Data acquisition mode

Acquisition time

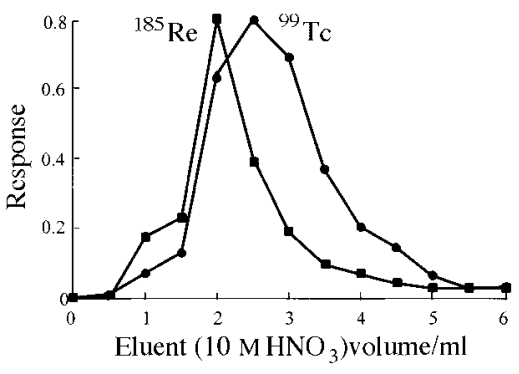

Fig. 3 Elution profiles for ${ }^{99} \mathrm{Tc}$ and ${ }^{185} \mathrm{Re}$.

\section{RESULTS AND DISCUSSION}

\section{Initial studies}

A key aspect of method development was to isolate Tc from the sea-water salts and at the same time to achieve analyte enrichment. This was achieved using Amberlite IRA-400 resin in the chloride form. Amberlite IRA-400 is a strong-base type anion exchanger with quaternary ammonium chloride functional groups attached to $8 \%$ cross-linked polystyrene and with pertechnate anion $\left(\mathrm{TcO}_{4}{ }^{-}\right)$should participate in the following exchange reaction:

$\mathrm{RN}\left(\mathrm{CH}_{3}\right)_{3}{ }^{+} \mathrm{Cl}^{-}$(solid) $+\mathrm{TcO}_{4}{ }^{-}$(solution)

$\rightleftharpoons \mathrm{RN}\left(\mathrm{CH}_{3}\right)_{3}{ }^{+} \mathrm{TcO}_{4}{ }^{-}$(solid) $+\mathrm{Cl}^{-}$(solution)

The same scheme is applicable to perrhenate anion $\left(\mathrm{ReO}_{4}{ }^{-}\right)$, hence the use of $\mathrm{Re}$ as a yield monitor. The enrichmentseparation capabilities of Amberlite IRA-400 resin were tested in the following way: $14 \mathrm{ml}$ of a standard solution containing $1.0 \mathrm{ng} 1^{-1}$ Tc and $0.1 \mu \mathrm{g} 1^{-1} \mathrm{Re}$ at $\mathrm{pH} \approx 8$ were applied to the column and Tc and Re underwent deposition. Then $0.5 \mathrm{ml}$ aliquots of eluent ( $10 \mathrm{M} \mathrm{HNO}_{3}$ ) were added, in succession, and the fractions collected. After dilution to $14 \mathrm{ml}$, each fraction was analysed by ICP-MS using the operating parameters given in Table 1. The elution profiles for $\mathrm{Tc}$ and $\mathrm{Re}$ are shown in Fig. 3 and indicate that $5 \mathrm{ml}$ of eluent are required to recover the analytes of interest. This finding is in accordance with independent studies ${ }^{8,11,13}$ and also confirms that $\mathrm{Re}$ is an appropriate yield monitor.

At this stage, it was thought prudent to check the contamination level in the nitric acid given that a relatively high concentration was used as eluent $(10 \mathrm{M})$. As shown in Fig. 4, the acid was contaminated with Mo (masses 92, 94, 95, 96, 97, 98 and 100) but, importantly, the lack of a signal response at $m / z 99$ ruled out contamination by ${ }^{99} \mathrm{Tc}$ or ${ }^{99} \mathrm{Ru}$. The high signal at $m / z \quad 90$ was due to $\mathrm{Zr}$ and $\mathrm{Zr}$ isotopes also contributed to the signals at masses 91,92 and 94 . Use of $R h$ as internal standard resulted in an intense signal at mass 103 .

The effectiveness of the proposed ion exchange procedure in rejecting the sea-water matrix ions was examined. A sample of sea-water $(14 \mathrm{ml}, \mathrm{pH} \approx 8)$ was applied to the column and the column was washed with $0.5 \mathrm{M} \mathrm{HNO}_{3}(2 \mathrm{ml})$. For elution, $5 \mathrm{ml}$ of $10 \mathrm{M} \mathrm{HNO}_{3}$ were added to the column and the eluate was collected and diluted to $14 \mathrm{ml}$ with high purity water. The

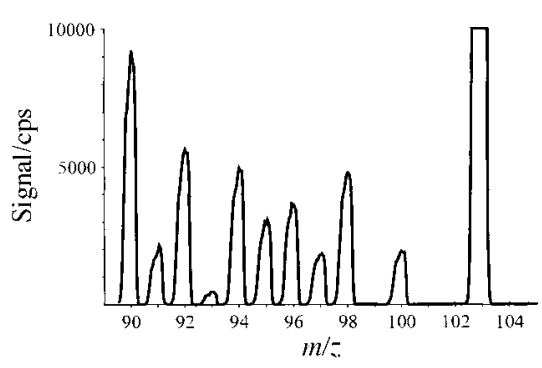

Fig. 4 Mass spectrum of the eluate (the sample contained no Tc). 
Table 2 Typical concentrations of elements in sea-water after ion exchange separation

\begin{tabular}{cccc} 
Element & Concentration $/ \mu \mathrm{g} 1^{-1}$ & Element & Concentration $/ \mu \mathrm{g} 1^{-1}$ \\
$\mathrm{Ba}$ & $4-8$ & $\mathrm{Mo}$ & $0.1-0.2$ \\
$\mathrm{Ca}$ & $10-20$ & $\mathrm{Na}$ & $35-40$ \\
$\mathrm{Co}$ & $0.005-0.01$ & $\mathrm{Ni}$ & $0.1-0.2$ \\
$\mathrm{Cu}$ & $0.5-1.0$ & $\mathrm{Pt}$ & $0.001-0.002$ \\
$\mathrm{Fe}$ & $3-20$ & $\mathrm{Ru}$ & $<0.001$ \\
$\mathrm{Hg}$ & $0.02-0.03$ & $\mathrm{Sr}$ & $0.4-0.6$ \\
$\mathrm{~K}$ & $1-2$ & $\mathrm{Ti}$ & $0.2-0.3$ \\
$\mathrm{Mg}$ & $4-10$ & $\mathrm{Zn}$ & $0.3-1.0$ \\
\hline
\end{tabular}

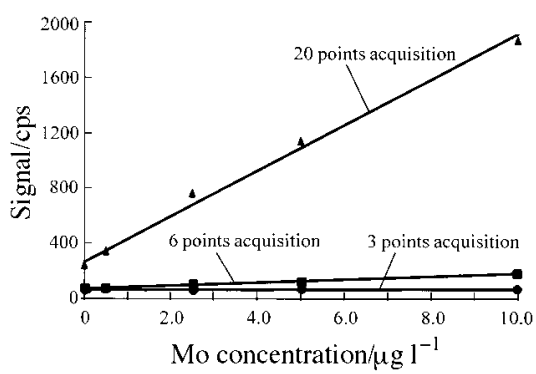

Fig. 5 Ion response (m/Z 99) as a function of Mo concentration and data acquisition mode.

elemental concentrations in the eluate are given in Table 2 and it is clear that concentrations of major elements such as $\mathrm{Na}$, $\mathrm{K}, \mathrm{Ca}, \mathrm{Mg}$ and $\mathrm{Ba}$ and elements which might cause isobaric interferences (e.g., $\left.{ }^{99} \mathrm{Ru}\right)$, polyatomic interferences $\left(\right.$ e.g. ${ }^{49} \mathrm{Ti}^{50} \mathrm{Ti}$, ${ }^{59} \mathrm{Co}^{40} \mathrm{Ar},{ }^{62} \mathrm{Ni}^{37} \mathrm{Cl},{ }^{63} \mathrm{Cu}^{36} \mathrm{Ar},{ }^{64} \mathrm{Zn}^{35} \mathrm{Cl},{ }^{98} \mathrm{Mo}^{1} \mathrm{H}$ and $\left.{ }^{98} \mathrm{Ru}^{1} \mathrm{H}\right)$ and doubly charged species (e.g., ${ }^{198} \mathrm{Pt}$ and ${ }^{198} \mathrm{Hg}$ ) were present at low concentrations $\left(\mu \mathrm{g}^{-1}-\mathrm{sub} \mu \mathrm{g} 1^{-1}\right.$ level). A synthetic multi-element solution was therefore prepared with the elements given in Table 2 (except $\mathrm{Ru}$ ) at concentrations 10 times greater than given in Table 2 and analysed. No change in ${ }^{99} \mathrm{Tc}^{+}$ion response was observed. As mentioned before, no interference from $\mathrm{Ru}$ was expected since $\mathrm{Ru}$ concentrations in marine waters are very low.

In contrast, molybdenum is present in sea-water at relatively high concentrations (approximately $7 \mu \mathrm{g}^{-1}$ ) and it was therefore necessary to check whether or not ${ }^{98} \mathrm{MoH}^{+}$was formed in significant concentrations. Standard solutions of Mo were therefore prepared and then measured. As shown in Fig. 5, no increase in count rate was observed as a function of Mo concentration when three point data acquisition was used. This data acquisition mode is the normal operating mode for quantitative analysis in which the three central peaks at the mass of interest are monitored. In the case of ${ }^{99} \mathrm{Tc}$ these peaks correspond to nominal masses $98.95,99.00$ and 99.05. For six point acquisition, the operating mode for semiquantitative analysis, a small increase in count rate was detected with increase in Mo concentration but overall the effect was not considered to be of sufficient magnitude to seriously compromise data. On the other hand, when 20 point acquisition was used, which is typical for recording mass spectra, the signal response $(m / z$ 99) increased linearly with increase in Mo concentration. Given that the contribution of $\mathrm{MoH}$ to the ion

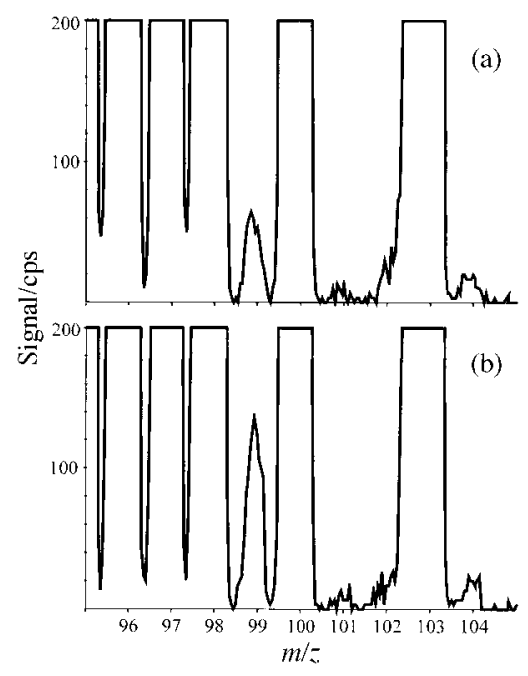

Fig. 6 Mass spectra of (a) unspiked and (b) spiked (2.0 $\left.\mathrm{ng} \mathrm{l}^{-1} \mathrm{Tc}\right)$ sea-water samples.

response at mass 99 is negligible, i.e., minimal signal for three and six point acquisition, it would seem that measurement at $m / z 99$ with 20 point acquisition was compromised by spectral overlap from the adjoining and relatively intense ${ }^{100} \mathrm{Mo}^{+}$. From these studies, it is concluded that for normal quantitative data acquisition, i.e., three points per mass, and when using USN with MD, interference related to naturally occurring Mo isotopes can be neglected.

\section{Analytical performance and application}

A surface sea-water sample collected from the Irish Sea at a site close to the Sellafield discharge and an uncontaminated open ocean water were analysed by the proposed method. The mass spectra for spiked and unspiked samples from the Irish Sea are given in Fig. 6 and the analytical data for the three samples are presented in Table 3 . In this analysis preconcentration was not utilised, i.e., a $14 \mathrm{ml}$ sample aliquot was processed and the final eluate volume was also $14 \mathrm{ml}$, yielding a limit of detection for Tc of $0.03 \mathrm{ng} \mathrm{l}^{-1}$. As shown in Table 3, the concentration of Tc in the Irish Sea sample was relatively high, $0.87 \mathrm{ng} \mathrm{l}^{-1}$, but this is consistent with sampling close to the point discharge. This value should be contrasted with the result for the open ocean water, i.e., Tc not detected.

The spike recovery values for the Irish Sea samples are acceptable, but in the absence of a certified sea-water reference material, independent check analysis based on $\beta$-counting is recommended for method validation. From the standpoint of accuracy, a positive bias could arise from the presence of co-existing $\mathrm{Ru}$ in the sea-water extract, but consideration of the mass spectra (Fig. 6) and signal intensities at $\mathrm{m} / \mathrm{z} 101$ and 104 together with the $\mathrm{Ru}$ isotope distribution pattern $\left({ }^{96} \mathrm{Ru}\right.$, $5.52 \% ;{ }^{98} \mathrm{Ru}, 1.88 \% ;{ }^{99} \mathrm{Ru}, 12.7 \% ;{ }^{100} \mathrm{Ru}, 12.6 \% ;{ }^{101} \mathrm{Ru}, 17.0 \%$; ${ }^{102} \mathrm{Ru}, 31.6 \%$; and ${ }^{104} \mathrm{Ru}, 18.7 \%$ ) indicate that the Ru contribution at $\mathrm{m} / \mathrm{z} 99$ is close to the ICP-MS background count level $\left(<10\right.$ counts $\left.\mathrm{s}^{-1}\right)$ and hence correction was not warranted.

A further aspect concerning the ultratrace determination of

Table 3 Spike recovery results

\begin{tabular}{lcccc} 
& $\begin{array}{c}\text { Tc original } \\
\text { concentration/ng } \text { 1 }^{-1}\end{array}$ & $\begin{array}{c}\text { Tc spike } \\
\text { concentration } / \text { ng 1 }^{-1}\end{array}$ & $\begin{array}{c}\text { Tc concentration } \\
\text { determined/ng 1 }\end{array}$ & Recovery $(\%)$ \\
High purity water & $<0.03$ & 2.00 & $2.09 \pm 0.10$ & $104 \pm 5$ \\
Open ocean water & $<0.03$ & 2.00 & $2.00 \pm 0.37$ & $100 \pm 18$ \\
Irish Sea & 0.87 & 2.00 & $2.75 \pm 0.33$ & $96 \pm 11$ \\
Number of replicates, $\mathrm{n}=3$. & & & & \\
\hline
\end{tabular}




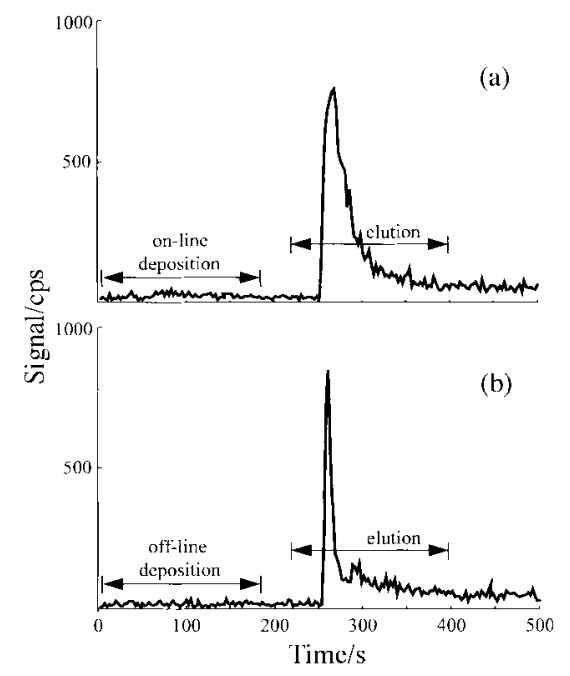

Fig. 7 Ion time response $\left({ }^{99} \mathrm{Tc}\right)$ using FI system: (a) high purity water ( Tc, $2.0 \mathrm{ng} \mathrm{l}^{-1}$ ) and (b) sea-water (Tc, $2.0 \mathrm{ng} \mathrm{l}^{-1}$ ).

Tc in marine waters is to be able to transfer the chemistry to a microcolumn-flow injection format. For this purpose a flow injection system with the Amberlite IRA-400 resin was configured as described under Experimental and used for processing high purity water and sea-water enriched with Tc $\left(2.0 \mathrm{ng}^{-1}\right)$. The ion time responses $\left({ }^{99} \mathrm{Tc}\right.$, one point acquisition, 0.1 set per mass) corresponding to the depositionelution cycles for the two samples are shown in Fig. 7. Based on this initial study, it is clear that the FI system affords a simple and rapid preconcentration-separation of Tc from seawater and further development work with the technique is warranted.

\section{CONCLUSIONS}

It has been demonstrated that ICP-MS utilising ultrasonic nebulisation with membrane desolvation in conjunction with ion exchange separation has considerable potential for the ultratrace determination of Tc in sea-water. Analyte preconcentration was not utilised in the present studies and further work is needed to extend the measurement capability to the sub$\mathrm{pg} 1^{-1}$ level (by processing relatively large sample volumes), to assess the performance relative to standard methodology based on $\beta$-counting techniques and to demonstrate potential in survey analyses. It is further proposed to develop and refine flow injection systems for field sampling and analyte enrichment.

Ahmet E. Eroglu is grateful to the Scientific and Technical Research Council of Turkey (TUBITAK) for the award of a fellowship. The authors are indebted to CETAC Technologies and Hewlett-Packard for their continued support.

\section{REFERENCES}

1 Beasley, T. M., and Lorz, H. V., J. Environ. Radioact., 1986, 3, 1.

2 Schulte, E. H., and Scoppa, P., Sci. Total Environ., 1987, 64, 163.

3 Fowler, S. W., Aston, S. R., Benayoun, G., and Parsi, P., Mar. Environ. Res., 1983, 8, 87.

4 Riley, J. P., and Siddiqui, S. A., Mar. Pollut. Bull., 1986, 17, 229.

5 Leonard, K. S., McCubbin, D., Brown, J., Bonfield, R., and Brooks, T., Mar. Pollut. Bull., 1997, 34, 628.

6 Nicholson, S., Sanders, T. W., and Blaine, L. M., Sci. Total Environ., 1993, 130-131, 275.

7 Morita, S., Tobita, K., and Kurabayashi, M., Radiochim. Acta, 1993, 63, 63.

8 Harvey, B. R., Williams, K. J., Lovett, M. B., and Ibbett, R. D., J. Radioanal. Nucl. Chem., 1992, 158, 417.

9 Riley, J. P., and Siddiqui, S. A., Anal. Chim. Acta, 1982, 139, 167.

10 Richter, R. C., Koirtyohann, S. R., and Jurisson, S. S., J. Anal. At. Spectrom., 1997, 12, 557.

11 Butterworth, J. C., Livens, F. R., and Makinson, P. R., Sci. Total Environ., 1995, 173/174, 293.

12 Beals, D. M., J. Radioanal. Nucl. Chem., 1996, 204, 253.

13 Hollenbach, M., Grohs, J., Mamich, S., Kroft, M., and Denoyer, E. R., J. Anal. At. Spectrom., 1994, 9, 927.

14 Kershaw, P. J., Sampson, K. E., McCarthy, W., and Scott, R. D., J. Radioanal. Nucl. Chem., 1995, 198, 113.

15 Igarashi, Y., Kim, C. K., Takaku, Y., Shiraishi, K., Yamamoto, M., and Ikeda, N., Anal. Sci., 1990, 6, 157.

16 Scott, R. D., Baxter, M. S., Hursthouse, A. S., McKay, K., Sampson, K., and Toole, J., Anal. Proc., 1991, 28, 382.

17 Chiappini, R., Taillade, J. M., and Brebion, S. J., J. Anal. At. Spectrom., 1996, 11, 497.

18 Applications of Inductively Coupled Plasma-Mass Spectrometry to Radionuclide Determinations, ed. Morrow, R. W., and Crain, J. S., ASTM (PCN) 04-012910-35, ASTM, Philadelphia, 1995.

19 Eroglu, A. E., McLeod, C. W., Leonard, K. S., and McCubbin, D., Spectrochim. Acta, Part B, in the press.

20 Rosenberg, R. J., J. Radioanal. Nucl. Chem., 1993, 171, 465.

21 Hursthouse, A. S., Baxter, M. S., McKay, K., and Livens, F. R., J. Radioanal. Nucl. Chem., 1992, 157, 281.

22 Smith, M. R., Wyse, E. J., and Koppenaal, D. W., J. Radioanal. Nucl. Chem., 1992, 160, 341.

23 McMahon, A. W., Appl. Radiat. Isot., 1992, 43, 289.

Paper $8 / 02414 F$

Received 30th March, 1998 Accepted 6th July, 1998 